\section{Nontransient learned helplessness ${ }^{1}$}

MARTIN E. P. SELIGMAN and DENNIS P. GROVES, ${ }^{2}$ Comell University, Ithaca, N.Y. 14850

Dogs who receive repeated, spaced exposure to inescapable electric shock in a Pavlovian hammock fail to escape shock in a shuttlebox 1 week later, while one session of inescapable shock produces only transient interference. Cage-raised beagles are more susceptible to interference produced by inescapable shock than are mongrels of unknown history. These results are compatible with learned helplessness and contradict the hypothesis that failure to escape shock is produced by transient stress.

Inescapable shocks profoundly disrupt later escape and avoidance responding in dogs. Twenty-four hours after a single treatment with inescapable shocks in a hammock, naive mongrel dogs fail to barrier-jump to escape shock in a shuttlebox (Overmier \& Seligman, 1967). Unlike untreated dogs who efficiently escape, preshocked dogs, although visibly upset, soon lie down in shock and fail to make escape movements. But this effect is transient. For if more than $48 \mathrm{~h}$ intervene between one session of inescapable shock in the hammock and shuttlebox testing, escape responding is normal.

This failure to escape has been interpreted as learned helplessness (Seligman \& Maier, 1967; Maier, Seligman, \& Solomon, 1969; Seligman, Maier, \& Solomon, in press). These investigators reasoned that during inescapable shock, S learned that shock was uncontrollable, i.e., that voluntary responding and shock termination were independent. The expectation that responding will produce relief provides the incentive for responding; learning that responding is ineffective undermines this incentive and produces failure to escape. They confirmed this hypothesis by demonstrating that shocks that could be escaped either by active (Seligman \& Maier, 1967) or passive responding (Maier, in press) in the hammock did not produce disruption but yoked inescapable shock did. Thus, shock per se does not produce helplessness, but only uncontrollable shock.

The dissipation in time described above does not follow from a learned helplessness interpretation. After all, learning that is present $24 \mathrm{~h}$ after training is usually present $48 \mathrm{~h}$ later. Miller \& Weiss (1969) suggested that since inescapable shock produces greater, although transitory, stress than escapable shock in rats (Weiss, 1968), the time course might result from stress dissipating in time rather than learned helplessness. Thus it is important to produce nontransient failure to escape, since it could not result from stress dissipating over time.

This study demonstrates nontransient failure to escape in dogs exposed to repeated inescapable shock sessions in the hammock. It also shows that dogs with restricted and known life histories are more sensitive to helplessness than supplier-provided dogs with unknown histories.

\section{SUBJECTS}

The Ss were 18 cage-raised beagle dogs and 15 adult mongrel dogs of unknown prelaboratory history, obtained from local suppliers. The beagles were raised singly in wire mesh cages and had not had any physical contact with other dogs after weaning and only minimal physical contact with people. After being received from the supplier, the mongrels were housed singly in wire cages. All dogs were 12-19 in. at the shoulder, 16-32 lb, and had ad lib access to food and water throughout the experiment.

\section{APPARATUS}

The apparatus is described fully by Overmier \& Seligman (1967). In brief, it consisted of two separate units: A Pavlovian harness, in which initial exposure to inescapable shock occurred, and a dog shuttlebox, in which escape/avoidance training was carried out.

The unit in which the Ss were exposed to inescapable shocks was a rubberized cloth hammock located inside a shielded, white, sound-reducing cubicle. Six-milliampere shock was applied to the $S$ through brass plate electrodes coated with electrode paste and taped to the footpads of the hind feet.

The unit in which the $S$ received escape/avoidance trials was a two-way shuttlebox with two black compartments separated by a barrier set at the S's shoulder height. The CS consisted of a sharp decrease in illumination. The UCS was $4.5-\mathrm{mA}$ scrambled electric shock applied through the grid floors from a $600-\mathrm{V}$ ac source. Whenever the $S$ crossed from one side of the shuttlebox to the other, photocell beams were interrupted and the trial was terminated.

\section{PROCEDURE}

The dogs were divided randomly into three groups: four-spaced, two-spaced, and controls. Approximately half of each group were cage-raised beagles and half were mongrels.

\section{Four-Spaced}

Ss in this group ( $N=7$ beagles, 5 mongrels) received four sessions of inescapable shock in the hammock spread out over 8 days, followed 7 days later by escape/avoidance training in the shuttlebox. In each hammock session, 60 5-sec inescapable shocks were presented. All shocks were unsignaled and the intershock interval ranged from 50 to $110 \mathrm{sec}$, averaging $80 \mathrm{sec}$. Hammock sessions occurred on Days 1, 3, 4, and 8; shuttlebox training (described below) occurred on Day 15.

\section{Two-Spaced}

Ss in this group $(\mathrm{N}=5$ beagles, 5 mongrels) were treated exactly like the four-spaced Ss, except that only two hammock sessions were given on Days 1 and 8 ; shuttlebox training occurred on Day 15.

\section{Controls}

These Ss $(\mathrm{N}=6$ beagles, 5 mongrels $)$ received no experience in the hammock, and were given shuttlebox training only. All Ss received 10 trials of instrumental escape/avoidance training in the shuttlebox. The CS-UCS onset interval was $10 \mathrm{sec}$. If the $\mathrm{Ss}$ crossed to the other compartment during this interval, the CS terminated and no shock was presented. If the $\mathrm{S}$ did not cross during the CS-UCS interval, shock came on and remained on until the $S$ crossed. If no response occurred within $60 \mathrm{sec}$ after CS onset, the trial was terminated and a 60-sec latency recorded. The average intertrial interval was $90 \mathrm{sec}$, with a range of $60-120 \mathrm{sec}$.

\section{RESULTS}

Table 1 presents the mean latency of response, mean failures to escape, and fraction of helpless Ss for the three groups divided by beagles and mongrels. Both the beagle and mongrel groups that received

\section{Table 1}

Mean Latency, Mean Number of Failures to Respond, and Fraction of $S s$ in Each Group Failing to Escape on 10 Out of 10 Trials

$\begin{array}{ccc} & \text { Four- } & \text { Two- } \\ \text { Mongrels } & \text { Spaced } & \text { Spaced }\end{array}$ Controls

\begin{tabular}{cccc} 
Mongrels & Spaced & Spaced & Controls \\
\hline Mean Latency & 39.98 & 20.23 & 17.08
\end{tabular}

\section{Mean Failures} to Respond

$6.00 \quad 2.00$

Fraction Failing

$10 / 10$ Trials

$3 / 5 \quad 1 / 5$

$0 / 5$

\section{Beagles}

\section{Mean Latency} in Seconds

$50.90 \quad 50.96 \quad 24.16$

Mean Failures to Respond

$\begin{array}{lll}8.00 & 7.60 \quad 1.84\end{array}$

Fraction Failin 10/10 Trials 
four-spaced inescapable shock sessions showed substantial interference with escape when tested 7 days later. The two-spaced sessions also produced some interference, particularly in the cage-raised beagles.

Collapsing across the beagle/mongrel factor, $t$ tests showed that the four-spaced group escaped more slowly $[t(22)=3.57$, $\mathrm{p}<.01]$ and made fewer responses $[\mathrm{t}(22)=4.17, \mathrm{p}<.001]$ than the controls. The two-spaced group made fewer responses $[\mathrm{t}(20)=2.14, \mathrm{p}<.05]$ and was somewhat slower than the controls $[t(20)=1.78, p<.10]$. The four-spaced and two-spaced groups did not differ. Thus, repeated exposures to inescapable shocks produced nontransient failure to escape.

Analyses of variance revealed that beagles jumped significantly more slowly than mongrels $[F(1,27)=6.49, p<.05]$ and failed to respond on more trials $[F(1,27)=4.90, p<.05]$. This effect seemed due wholly to the two-spaced condition: In this group, beagles were slower to respond $[\mathrm{F}(1,27)=7.74$, $\mathrm{p}<.01]$ than mongrels and made fewer responses $[F(1,27)=6.17, p<.05]$ than mongrels. Differences between beagles and mongrels did not approach significance in either the four-spaced or control condition. Thus, beagles of known life history are more sensitive to inescapable shock than mongrels of unknown past experience.

\section{DISCUSSION}

Repeated, spaced exposure to inescapable shocks interferes with escape responding 1 week later, and cage-raised beagles are more susceptible than mongrels of unknown history.

These results bear on the two current hypotheses concerning the failure to escape caused by uncontrollable shock.

\section{Stress}

Uncontrollable shock produces more stress than controllable shock (cf. Seligman, Maier, \& Solomon, in press). Miller \& Weiss (1969) suggested that this stress causes failure to escape shock $24 \mathrm{~h}$ after inescapable shock: "Perhaps the dogs typically gave up before they happened to jump over the shoulder-high barrier because of a physiological depression, much as one of us might give up a difficult task more quickly if we were sick with influenza." Weiss (1968) provided evidence for the transitory nature of such stress in rats: Rats that received uncontrollable shock showed a reduced weight gain for the first $24 \mathrm{~h}$, but after that their weigh gain paralleled the groups that received controllable shock or no shock. This suggests that $48 \mathrm{~h}$ after inescapable shock the depression has dissipated, and therefore escape is normal in dogs.

It is clear that a theory that invokes transient stress as an explanation of failure to escape cannot account for nontransient helplessness demonstrated in this study.

Learned Helplessness

The helplessness hypothesis claims that dogs fail to escape because they have learned that shock termination is independent of responding during inescapable shock. Such learning has two effects: It reduces the probability that responses will be initiated during shock and it interferes with S's associating successful responses with shock termination.

In order to account for the time-course results and the results of this study, the helplessness hypothesis calls upon the notion of proactive interference (PI). When an adult dog of unknown past history arrives at our laboratory, it has presumably had a lifetime of experience with many responses that produced relief. If it then receives one session of inescapable shock and learns that responding and relief are independent, PI from $h$ is earlier experiences might affect retention. Braud, Wepman, \& Russo (1969) reported considerable positive transfer of helplessness across settings, and it seems likely that negative transfer should occur from mastery to helplessness across settings. Since PI increases with time, it is possible that $24 \mathrm{~h}$ after inescapable shock the dog would remember that responding and relief were independent, but if $48 \mathrm{~h}$ elapsed this might have been forgotten. Multiple sessions in which responding and shock are independent should enhance learning and reduce the effects of PI, producing nontransient helplessness. Cage-reared dogs with limited opportunity to learn that responding controls their environment should have little PI and thus be more susceptible to helplessness.

In conclusion, we believe that a learned helplessness view of inescapable shock, rather than a transient stress view, is more compatible with our data. The proactive interference of experience with control seems a more likely explanation of the time course of helplessness caused by one exposure to inescapable shock than an unspecified motivational state that dissipates in time. We do not reject, however, the possibility that leaming that shock is uncontrollable produces a motivational depletion not unlike clinical depression in humans, and that this contributes to the failure to escape shock. At this point, direct evidence of physiological changes is necessary to substantiate this. Finally, we suggest that both failure to escape and the greater stress produced by inescapable shock have a common cause: learning that responding and trauma are independent.

\section{REFERENCES}

BRAUD, W., WEPMANN, B., \& RUSSO, D. Task and species generality of the "helplessness" phenomenon. Psychonomic Science, 1969, 16. 154-155.

MAIER, S. Failure to escape traumatic shock: Incompatible skeletal motor responses or learned helplessness? Learning \& Motivation, in press.

MAIER, S., SELIGMAN. M.. \& SOLOMON. R. Pavlovian fear conditioning and learned helplessness: Effects on escape and avoidance bheavior of a) CS-US contingency and b) the independence of the US and voluntary responding. In B. A. Campbell and R. Church (Eds.), Punishment. New York: Appleton- entury-( rotis, 1969. Pp. 299.342.

WILLER, V.. \& WLISS. J. Effects of the somatic or visceral responses to punishment in $B . A$. Campbell and R. Church (Eds.). Punishment Vew York: Appleton-Cintury-Crotts. 1969. Pp. 3+3-372.

OVERMIER, J. B., \& SELIGMAN, M. E. P. Effects of inescapable shock upon subsequent escape and avoidance responding. Journal of Comparative \& Physiological Psychology, 1967, 63, 28-33.

SELIGMAN, M., \& MAIER, S. Failure to escape traumatic shock. Joumal of Experimental Psychology, 1967, 74, 1-9.

SELIGMAN, M., MAIER, S., \& SOLOMON, R. Unpredictable and uncuntrollable aversive events. In F. R. Brush (F.d.), Aversive conditioning and learning. Sew York: Academic Press, in press.

WEISS, J. Effects of coping responses on stress. Journal of Comparative \& Physiological Psychology, 1968, 65, 251-260. NOTES

1. This research was supported by National Institute of Mental Health Grant MH 16546-01 to M. Seligman. The authors thank S. Mater. J. B. Overmier. R. L. Solomon, and J. Weiss for helpful comments on an earlier draft of the manuscript.

2. Now at the University of Michigan. 